\title{
On $\delta^{*}$-Supplemented Modules
}

\author{
Alaa Abbas Elewi ${ }^{1}$ \\ Tamadher Arif Ibrahiem ${ }^{2 *}$
}

Received 13/12/2018, Accepted 25/6/2019, Published 1/3/2020

This work is licensed under a Creative Commons Attribution 4.0 International License.

\begin{abstract}
.
The main goal of this paper is to introduce and study a new concept named $\delta^{*}$-supplemented which can be considered as a generalization of $\mathrm{W}$ - supplemented modules and $\delta$-hollow module. Also, we introduce a $\delta^{*}$-supplement submodule. Many relationships of $\delta^{*}$-supplemented modules are studied. Especially, we give characterizations of $\delta^{*}$-supplemented modules and relationship between this kind of modules and other kind modules for example every $\delta$-hollow ( $\delta$-local) module is $\delta^{*}$-supplemented and by an example we show that the converse is not true.
\end{abstract}

Key words: $\delta$-hollow, $\delta$-small submodule, $\delta^{*}$ - supplement, $\delta^{*}$ - supplemented, W-supplemented.

\section{Introduction:}

Throughout this paper all rings are commutative with identity and all modules are unitary left R-modules. A proper submodule $\mathrm{N}$ of $\mathrm{M}$ is called "small $(\mathrm{N}<<\mathrm{M})$, if $\mathrm{N}+\mathrm{K}=\mathrm{M}$, for $\mathrm{K} \leq \mathrm{M}$ implies $\mathrm{K}=\mathrm{M}$ " (1). Equivalently a submodule $\mathrm{N}$ of a module $\mathrm{M}$ is called "small $(\mathrm{N}<<\mathrm{M})$, if $\mathrm{N}+\mathrm{K} \neq \mathrm{M}$, for every proper submodule $\mathrm{N}$ of $\mathrm{M}$ "(2). A module $\mathrm{M}$ is called "singular (nonsingular) if $\mathrm{Z}(\mathrm{M})=\mathrm{M},(\mathrm{Z}(\mathrm{M})=(0))$, where $\mathrm{Z}(\mathrm{M})=\left\{\mathrm{x} \in \mathrm{M}: \operatorname{ann}(\mathrm{x}) \leq_{\mathrm{e}}\right.$ $\mathrm{R}$ \}"(1). A submodule $\mathrm{N}$ of a module $\mathrm{M}$ is said to be " $\delta$-small if $\mathrm{N}+\mathrm{K}=\mathrm{M}$ with $\frac{M}{K}$ is singular implies $\mathrm{K}=$ M" (1). A submodule $\mathrm{N}$ of a module $\mathrm{M}$ is called " supplement of a submodule $N$ of $M$ if $N$ is a minimal element in the set of submodule $\mathrm{L} \leq \mathrm{M}$ with $\mathrm{N}+\mathrm{L}=\mathrm{M}$ "(3). Equivalently, $\mathrm{M}=\mathrm{N}+\mathrm{K}$ and $\mathrm{N} \cap \mathrm{K}<<$ $\mathrm{N}$ "(3). And a module $\mathrm{M}$ is called a "supplemented module if every submodule of $M$ has a supplemented in M" (4, p.348). An R-module M is called a "semisimple R-module if $\operatorname{Soc}(\mathrm{M})=\mathrm{M}$ (where $\operatorname{Soc}(\mathrm{M})=\Sigma \mathrm{A}$, where $\mathrm{A}$ is simple submodule of M"(4). It is known that an R-module $\mathrm{M}$ is a "semisimple module if and only if every submodule of M is a direct summand" (4).

In this paper we introduce the concept of $\delta^{*}$ supplemented module: "M is called $\delta^{*}$ supplemented module if for every semisimple

1 Department of Mathematics, College of Science, University of Baghdad, Baghdad, Iraq

${ }^{2}$ Department of Mathematics, College of Science for Women, University of Baghdad, Baghdad, Iraq

*Corresponding

author: submodule $\mathrm{N}$ of $\mathrm{M}$, there exist a submodule $\mathrm{K}$ such that $\mathrm{M}=\mathrm{N}+\mathrm{K}$ and $\mathrm{N} \cap \mathrm{K}<<\mathrm{K}^{\prime \prime}$ and investigate characterizations and properties of $\delta^{*}$-supplemented modules. Also the relationship between this kind of modules and some other modules is given.

\section{Preliminary}

\section{Definitions 1}

1. A submodule $\mathrm{N}$ of an $\mathrm{R}$-module $\mathrm{M}$ is said to be " $\delta$ - supplement of a submodule $\mathrm{K}$ of $\mathrm{M}$ if $\mathrm{N}+\mathrm{K}=$ $\mathrm{M}$ and $\mathrm{N} \cap \mathrm{K}<\delta<\mathrm{N} "$ (1). And a module $\mathrm{M}$ is called a " $\delta$-supplemented module if for every submodule of $\mathrm{M}$ has a $\delta$-supplement in M" (1).

2. A submodule $\mathrm{N}$ of an R-module $\mathrm{M}$ is called " $\delta$ small if $\mathrm{N}+\mathrm{K}=\mathrm{M}$ with $\frac{M}{K}$ is singular implies $\mathrm{K}=$ M" (1).

3. Let $\mathrm{M}$ be an R-module, then $\delta(\mathrm{M})=$ $\cap\{\mathrm{N} \leq \mathrm{M} ; \mathrm{M} / \mathrm{N}$ is singular simple $\}=\sum_{\substack{\mathrm{N}<<\mathrm{M} \\ \delta}} \mathrm{N}(5)$.

\section{Remarks and examples 2}

1. Obviously, every small submodule of an Rmodule $\mathrm{M}$ is $\delta$-small, but the converse is not true integral, for example $\mathbb{Z}_{2}$ as $\mathbb{Z}$-module is $\delta$ small but not small(1)

2. If $\mathrm{A}$ is a supplement of $\mathrm{B}$ in an $\mathrm{R}$ - module $\mathrm{M}$, then $\mathrm{B}$ need not to be a supplement of A in $\mathrm{M}$. For example in the $\mathbb{Z}$-module $\mathbb{Z}_{4}$, we have $\mathbb{Z}_{4}$ is a supplement of $\{\overline{0}, \overline{2}\}$. It is clear that $\{\overline{0}, \overline{2}\}$ is not a supplement of $\mathbb{Z}_{4}$. 
3. Supplement needs not to be existing for example the module $2 \mathbb{Z}$ of the module $\mathbb{Z}$ as $\mathbb{Z}$ module has no supplement (since the only small submodule of $\mathbb{Z}$ are $\{0\}, 2 \mathbb{Z}$ and $\mathbb{Z}$ is an indecomposable.

4. If $\mathrm{N}, \mathrm{K}$ are two a submodule of an R-module $\mathrm{M}$ such that $\mathrm{K}$ is a supplement of $\mathrm{N}$, then:

a) If $\mathrm{W}+\mathrm{K}=\mathrm{M}$, for some $\mathrm{W}$ submodule of $\mathrm{N}$, then $\mathrm{K}$ is a supplement of $\mathrm{W}(4,4.41-1, \mathrm{p} .348)$.

b) For $\mathrm{L} \leq \mathrm{N}, \frac{\mathrm{K}+\mathrm{L}}{\mathrm{L}}$ is a supplement of $\frac{N}{L}$ in $\frac{M}{L}$ $(4,4.41-7$, p.348)

Definition 3 (6) Let $M$ be an R-module. $M$ is said to be $\mathrm{W}$-supplemented if every semisimple submodule of $\mathrm{M}$ has a supplement in $\mathrm{M}$.

Definition 4 (7)((1)) An R-module $M$ is called lifting ( $\delta$-lifting if and only if for every submodule $\mathrm{N}$ of $\mathrm{M}$ there exists submodule $\mathrm{K}, \mathrm{K}^{\prime} \leq \mathrm{M}$ such that $\mathrm{M}=\mathrm{K} \oplus \mathrm{K}^{\prime}$ with $\mathrm{K} \leq \mathrm{N}$ and $\mathrm{N} \cap \mathrm{K}^{\prime}<<\mathrm{K}^{\prime}\left(\mathrm{N} \cap \mathrm{K}^{\prime}<<\mathrm{K}^{\prime}\right)$.

Lemma 5 (6) Let $M=N+L, L$ is a submodule of an $\mathrm{R}$-module $\mathrm{M}$ and $\mathrm{N}$ is semisimple submodule of $\mathrm{M}$. Then $\mathrm{M}=\mathrm{N}^{\prime} \oplus \mathrm{L}$ for some $\mathrm{N}^{\prime} \leq \mathrm{N}$.

\section{Characterization of $\delta^{*}$-supplemented}

Definition 6 An R-module $M$ is called $\delta^{*}$ supplemented module if for every semisimple submodule $\mathrm{N}$ of $\mathrm{M}$, there exists a submodule $\mathrm{K}$ such that $\mathrm{M}=\mathrm{N}+\mathrm{K}$ and $\mathrm{N} \cap \mathrm{K}<<\mathrm{K}$.

Definition 7 A submodule $\mathrm{N}$ of an R-module $\mathrm{M}$ is called $\delta^{*}$-supplement of a submodule $\mathrm{L}$ of $\mathrm{M}$ means that $\mathrm{N}$ is semisimple submodule of $\mathrm{M}$ such that $\mathrm{M}=$ $\mathrm{N}+\mathrm{L}$ with $\mathrm{N} \cap \mathrm{L}<<\mathrm{N}$.

\section{Examples and Remarks 8}

1. Every supplemented module is $\delta^{*}$ supplemented module. But the converse is not true in general for example: $Q$ as $\mathbb{Z}$ module is $\delta^{*}$ - supplemented since $\mathrm{Q}$ has no semisimple submodule, but $\mathrm{Q}$ is not supplemented module.

2. Every $\mathrm{W}$-supplemented module is $\delta^{*}$ supplemented.

Proof The proof is clear since every small submodule is $\delta$-small (1).

3. If $\mathrm{M}$ is singular module then $\mathrm{M}$ is $\delta^{*}$ supplemented iff $\mathrm{M}$ is $\mathrm{W}$ - supplemented.

Proof Since $M$ is singular then $\mathrm{N} \cap \mathrm{K}<<\mathrm{K}$ iff $\mathrm{N} \cap \mathrm{K}$ $\delta$

$<<\mathrm{K}$ ( where $\mathrm{K}$ and $\mathrm{N}$ are two submodules of $\mathrm{M}$.

4. Every direct summand of is $\delta^{*}$ supplemented module is is $\delta^{*}$ supplemented
Proof Suppose that $\mathrm{M}$ is $\delta^{*}$-supplemented module and $\mathrm{M}=\mathrm{M}_{1} \oplus \mathrm{M}_{2}$. Let $\mathrm{N}$ semisimple submodule of $M_{1}$. So, there exists a submodule $K$ of $M$ such that $\mathrm{M}=\mathrm{N}+\mathrm{K}$ with $\mathrm{N} \cap \mathrm{K}<<\mathrm{K}$. Thus $\mathrm{M}_{1}=\mathrm{N} \oplus\left(\mathrm{M}_{1} \cap \mathrm{K}\right)($ by modular law). Therefore $\mathrm{M}_{1}=\mathrm{L} \oplus\left(\mathrm{M}_{1} \cap \mathrm{K}\right)$, for some $\mathrm{L} \leq \mathrm{N}$ ( by lemma 5). Hence $\mathrm{M}_{1} \cap \mathrm{K} \leq{ }^{\oplus} \mathrm{M}_{1}$. Now, $\mathrm{N} \cap \mathrm{K}<<_{\delta} \mathrm{K} \leq \mathrm{M}$, then by $(7$, proposition(1.2.10)) $\mathrm{N} \cap \mathrm{K}<<$ M. Since $\mathrm{N} \cap \mathrm{K} \leq$ $\mathrm{M}_{1} \cap \mathrm{K} \leq{ }^{\oplus} \mathrm{M}$, therefore $\mathrm{N} \cap\left(\mathrm{M}_{1} \cap \mathrm{K}\right)=\mathrm{M}_{1} \cap(\mathrm{N} \cap \mathrm{K})=$ $\mathrm{N} \cap \mathrm{K}<<\mathrm{M}_{1} \cap \mathrm{K}$ (7, proposition1.2.10).

5. If $\mathrm{A}$ is $\delta^{*}$-supplement of $\mathrm{B}$ in a module $\mathrm{M}$, then $\mathrm{B}$ needs not to be $\delta^{*}$-supplemented of A in M. For example: $\mathbb{Z}_{2}$ is $\delta^{*}$-supplement of $\mathbb{Z}_{6}$ in $\mathbb{Z}_{6}$ but $\mathbb{Z}_{6}$ is not $\delta^{*}$-supplemented of $\mathbb{Z}_{2}$ in $\mathbb{Z}_{6}$, since $\mathbb{Z}_{2} \oplus \mathbb{Z}_{6}=\mathbb{Z}_{6}$ and $\mathbb{Z}_{2} \cap \mathbb{Z}$ ${ }_{6}=\mathbb{Z}_{2}, \mathbb{Z}_{2}<<\mathbb{Z}_{2}$ but $\mathbb{Z}_{2}$ is not $\delta$-small in $\mathbb{Z}_{6}$.

6. Let $\mathrm{M}$ be an $\mathrm{R}$-module with $\operatorname{Rad}(\mathrm{M})=0$, then $M$ is semisimple supplemented module iff $\mathrm{M}$ is $\delta^{*}$ - supplemented .

Proof $\Rightarrow)$ By $(1)$ every supplemented module is $\delta^{*}$ supplemented

$\Leftarrow)$ Let $\mathrm{K}$ be a submodule of $\mathrm{M}$, thus $\mathrm{K}$ is semisimple, but $\mathrm{M}$ is $\delta^{*}$ - supplemented ,thus there exists $\mathrm{N} \leq \mathrm{M}$ such that $\mathrm{N}+\mathrm{K}=\mathrm{M}$ and $\mathrm{N} \cap \mathrm{K}<<\mathrm{K} \leq$ $\delta$

$\delta(M)$. But $\delta(M) \leq \operatorname{Rad}(M)=0$, thus $N \cap K=0<<K$ and hence $\mathrm{M}$ is a supplemented module.

Now, we have the following

Remark 9 Let $\mathrm{M}$ be an R-module, then $\mathrm{M}$ is $\delta^{*}$ supplemented iff every semisimple submodule $\mathrm{N}$ of $\mathrm{M}$, there exists a submodule $\mathrm{N}^{\prime}$ such that $\mathrm{M}=\mathrm{N}^{\prime} \oplus \mathrm{L}$ and $\mathrm{N} \cap \mathrm{L}<<\mathrm{L}$.

Proof Let $\mathrm{N}$ be a semisimple submodule of $\mathrm{M}$, since $M$ is $\delta^{*}$ - supplemented and $M=N+L$ and $\mathrm{N} \cap \mathrm{L}<<$ L, then by lemma 5 there exists $\mathrm{N}^{\prime} \leq \mathrm{N}$ such that $\mathrm{M}=\mathrm{N}^{\prime} \oplus \mathrm{L}$ and $\mathrm{N} \cap \mathrm{L}<\delta$ L . Conversely, let $\mathrm{N}$ be a semisimple submodule of $\mathrm{M}$. Then by assumption, there exists $\mathrm{N}^{\prime} \leq \mathrm{N}$ such that $\mathrm{M}=\mathrm{N}^{\prime} \oplus \mathrm{L}$ and $\mathrm{N} \cap \mathrm{L}<<$ L implies M=N+L. Hence M is $\delta^{*}$-supplemented.

Proposition 10 Let $M$ be a $\delta^{*}$ - supplemented, then every semisimple submodule of $\frac{M}{\delta(M)}$ is a direct summand. 
Proof. Suppose that $M$ is a $\delta^{*}$ - supplemented. Then every very semisimple submodule of $\frac{M}{\delta(M)}$ has the form $\frac{N}{\delta(M)}$ for semisimple submodule $\mathrm{N}$ of $\mathrm{M}$ and $\delta(M) \subseteq N$. So there exist a submodule $\mathrm{L}$ of $\mathrm{M}$ such that $\mathrm{M}=\mathrm{N}+\mathrm{L}$ and $\mathrm{N} \cap \mathrm{L}<<\mathrm{L}$ implies $\mathrm{N} \cap \mathrm{L} \subseteq \delta(M)$. $\delta$

Now, $\mathrm{N} \cap(\mathrm{L}+\delta(M))=(\mathrm{N} \cap \mathrm{L})+\delta(M)=\delta(M)$. So, $\frac{M}{\delta(M)}=\frac{N+L}{\delta(M)}=\frac{N}{\delta(M)} \oplus \frac{L+\delta(M)}{\delta(M)}$. Thus $\frac{N}{\delta(M)}$ is a direct summand of $\frac{M}{\delta(M)}$.

The following theorem gives a characterization for $\delta^{*}$ - supplemented module.

Theorem 11 Let $M$ be an R-Module, then the following statements are equivalent:-

1. $\mathrm{M}$ is $\delta^{*}$ - supplemented.

2. For every semisimple submodule $\mathrm{N}$ of $\mathrm{M}$, there is a decomposition $\mathrm{M}=\mathrm{M}_{1} \oplus \mathrm{M}_{2}$ such that $\mathrm{M}_{1} \leq \mathrm{N}$ and $\mathrm{N} \cap \mathrm{M}_{2}<<\mathrm{M}_{2}$.

3. Every semisimple submodule $\mathrm{N}$ of $\mathrm{M}$ can be written as $\mathrm{N}=\mathrm{A} \oplus \mathrm{B}$, where $\mathrm{A}$ is a direct summand of $\mathrm{M}$ and $\mathrm{B}<<\mathrm{M}$. $\delta$

Proof (1) $\rightarrow$ (2) Following Remark (9)

$(2) \rightarrow(3)$ Let $N$ be a semisimple submodule of $M$, then by(2), $\mathrm{M}=\mathrm{A} \oplus \mathrm{B}$ for some $\mathrm{A} \leq \mathrm{N}$ and $\mathrm{N} \cap \mathrm{B}<<$

B. By Modular Law, $\mathrm{N}=\mathrm{A} \oplus(\mathrm{N} \cap \mathrm{B})$ ( where $\mathrm{A} \cap \mathrm{N} \cap \mathrm{B}=0)$. Since $\mathrm{N} \cap \mathrm{B}<<\mathrm{B} \subseteq \mathrm{M}$, then by $(7$,

proposition 2.1.10), we have and $\mathrm{N} \cap \mathrm{B}<<\mathrm{M}$.

(3) $\rightarrow$ (1) Let $\mathrm{N}$ be a semisimple submodule of $\mathrm{M}$, thus by the hypothesis $\mathrm{N}=\mathrm{A} \oplus \mathrm{B}$, where $\mathrm{A}$ is a direct summand of $\mathrm{M}$ and $\mathrm{B}<<\mathrm{M}$. Now, $\mathrm{M}=\mathrm{A} \oplus \mathrm{k}$ , for $\mathrm{K} \leq \mathrm{M}$ and $\mathrm{A} \leq \mathrm{N}$, then $\mathrm{M}=\mathrm{N}+\mathrm{K}=(\mathrm{A} \oplus \mathrm{B})+\mathrm{K}=$ $\mathrm{A} \oplus(\mathrm{B}+\mathrm{K})$ and $(\mathrm{A} \oplus \mathrm{B}) \cap \mathrm{K}=(\mathrm{A} \cap \mathrm{K}) \oplus(\mathrm{B} \cap \mathrm{K})=0 \oplus$ $(\mathrm{B} \cap \mathrm{K})=\mathrm{B} \cap \mathrm{K}$. Since $\mathrm{B}<<\mathrm{M}$ and $\mathrm{K}<<\mathrm{K}$, then $\mathrm{B} \cap \mathrm{K}<<\mathrm{M} \cap \mathrm{K}=\mathrm{K}$. That is $\mathrm{M}=\mathrm{N}+\mathrm{K}$ and $\mathrm{N} \cap \mathrm{K}=$

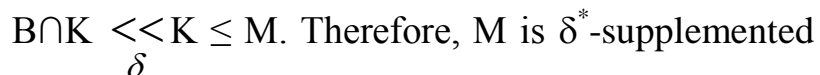
module.

The following proposition is similar to (5, proposition 2.3).

Proposition 12 Let $\mathrm{M}$ be an R-module $\mathrm{A}$ and $\mathrm{B}$ are submodules of $\mathrm{M}$ such that $\mathrm{A} \leq \mathrm{B}$. Then:

1. If $\mathrm{B}$ is a $\delta^{*}$ - supplement submodule in $\mathrm{M}$, then $\frac{B}{A}$ is a $\delta^{*}$ - supplement submodule in $\frac{M}{A}$.
2. If $\mathrm{B}$ is a $\delta^{*}$ - supplement summand of $\mathrm{C}$ in $\mathrm{M}$, then $\frac{C+A}{A}$ is a $\delta^{*}$ - supplement of $\frac{B}{A}$ in $\frac{M}{A}$

Proof 1 Suppose that B is a $\delta^{*}$ - supplemented of $\mathrm{N}$ in $\mathrm{M}$, so $\mathrm{B}$ is semisimple submodule of $\mathrm{M}$ with $\mathrm{M}=$ $\mathrm{B}+\mathrm{N}$ such that $\mathrm{B} \cap \mathrm{N}<<<$ N. Now, $\frac{B}{A}$ is semisimple submodule in $\frac{M}{A}$. Then $\frac{M}{A}=\frac{B}{A}+\frac{N+A}{A}$ and $\frac{B}{A} \cap \frac{N+A}{A}=$ $\frac{B \cap(N+A)}{A}=\frac{A+(B \cap N)}{A}<<\frac{N+A}{A}$ and so $\frac{B}{A}$ is a $\delta^{*}-$ supplemented $\quad \operatorname{in} \frac{M}{A}$, where $\quad \mathrm{f}: \mathrm{A} \rightarrow \frac{N+A}{A}$ is a homomorphism and $\mathrm{A} \cap \mathrm{B}<<\mathrm{N}$, implies $\mathrm{f}(\mathrm{A} \cap \mathrm{B})$ $=\frac{(\mathrm{A} \cap \mathrm{B})+A}{A}<<\frac{N+A}{A}$

2. It is similar to proof 1 .

Corollary 13 Every factor of $\delta^{*}$ - supplemented module is $\delta^{*}$ - supplemented module.

Remark 14 An inverse image of $\delta^{*}$ - supplemented module needed not $\delta^{*}$ - supplemented. For example: Let $\mathrm{f}: \mathbb{Z} \rightarrow \mathbb{Z}_{6}$ be an epimorphism $\frac{\mathbb{Z}}{(6)} \approx \mathbb{Z}_{6}$ and $\mathbb{Z}_{6}$ is semisimple but $\mathrm{f}^{-1}\left(\mathbb{Z}_{6}\right)=\mathbb{Z}$ and $\mathbb{Z}$ is not semisimple.

Proposition 15 Let $M$ be an R-module and $A \leq B \leq$ M. If $\frac{B}{A}$ is $\delta^{*}$-supplement in $\frac{M}{A}$ and $\mathrm{A}$ is a $\delta^{*}$ supplement in M. Then B is a $\delta^{*}$ - supplement in M. Proof Suppose that A is A $\delta^{*}$ - supplemented of $\mathrm{L}$ in $\mathrm{M}$ and $\frac{B}{A}$ is $\delta^{*}$ - supplement of $\frac{N}{A} \operatorname{in} \frac{M}{A}$. Thus, $\frac{M}{A}=\frac{B}{A}+$ $\frac{N}{A}$ and $\frac{B}{A} \cap \frac{N}{A}<<\frac{N}{A}$, also $\mathrm{M}=\mathrm{A}+\mathrm{L}$ and $\mathrm{A} \cap \mathrm{L} \underset{\delta}{<}<\mathrm{L}$ with each of $\mathrm{A}$ and $\frac{B}{A}$ is semisimple. Since $\mathrm{B}=$ $\mathrm{B} \cap(\mathrm{A}+\mathrm{L})=\mathrm{A}+(\mathrm{B} \cap \mathrm{L})$ and $\frac{B}{A} \cap \frac{N}{A}=\frac{B \cap N}{A}<<\frac{N}{A}$, that is $\frac{B \cap N \cap L}{A \cap L}<\delta \frac{N}{A \cap L}$. Notice that, $\mathrm{A} \cap \mathrm{L} \underset{\delta}{<}<\mathrm{L} \leq \mathrm{N}$ and hence $\mathrm{A} \cap \mathrm{L}<<\mathrm{N}$. Furthermore $\mathrm{B} \cap(\mathrm{N} \cap \mathrm{L})<<\mathrm{N}(7$, $\delta \quad \delta \quad \mathrm{N}=$ proposition 2.1.10). By Modular Law, $\mathrm{N}=$ $\mathrm{A}+(\mathrm{N} \cap \mathrm{L})$, but $\mathrm{B}=\mathrm{B}+\mathrm{A}$, then $\mathrm{M}=\mathrm{B}+\mathrm{N}=\mathrm{B}+(\mathrm{N} \cap \mathrm{L})$. Therefore $\mathrm{B}$ is $\delta^{*}$ - supplement in $\mathrm{M}$.

Now, we have the following proposition

Proposition 16 Let $M=M_{1} \oplus M_{2}$ if $A$ is $\delta^{*}$ supplement of $A_{1}$ in $M_{1}$ and $B$ is $\delta^{*}$-supplement of $\mathrm{B}_{1}$ in $\mathrm{M}_{2}$, then $\mathrm{A} \oplus \mathrm{B}$ is $\delta^{*}$ - supplement of $\mathrm{A}_{1} \oplus \mathrm{B}_{1}$ in M.

Proof Since each of $A$ and $B$ is semisimple, then so is $A \oplus B$. Now, $M_{1}=A+A_{1}$ with $A \cap A_{1}<<A_{1}$ and $\mathrm{M}_{2}=\mathrm{B}+\mathrm{B}_{1}$ with $\mathrm{B} \cap \mathrm{B}_{1}<<\mathrm{B}_{1}$, then $\mathrm{M}=\left(\mathrm{A}+\mathrm{A}_{1}\right) \oplus$ $\left(B+B_{1}\right)=(A \oplus B)+\left(A_{1} \oplus B_{1}\right)$. Since $\left(A \cap A_{1}\right) \oplus$ $\left(\mathrm{B} \cap \mathrm{B}_{1}\right)<<\mathrm{A}_{1} \oplus \mathrm{B}_{1}$. So, $(\mathrm{A} \oplus \mathrm{B})+\left(\mathrm{A}_{1} \oplus \mathrm{B}_{1}\right)<<$ 
$\mathrm{A}_{1} \oplus \mathrm{B}_{1}$. That is $\mathrm{A} \oplus \mathrm{B}$ is a $\delta^{*}$ - supplement of $\mathrm{A}_{1} \oplus$ $\mathrm{B}_{1}$. So that $(\mathrm{A} \oplus \mathrm{B}) \cap\left(\mathrm{A}_{1} \oplus \mathrm{B}_{1}\right)<\delta<\mathrm{A}_{1} \oplus \quad \mathrm{B}_{1}$.

Therefore $\mathrm{A} \oplus \mathrm{B}$ is $\delta^{*}$ - supplement of $\mathrm{A}_{1} \oplus \mathrm{B}_{1}$.

Proposition 17 Let $\mathrm{M}_{1}$ and $\mathrm{M}_{2}$ are two submodules of $M$ with $M_{1}$ is $\delta^{*}$ - supplemented and $M_{1}+M_{2}$ has $\delta^{*}$ - supplement in $\mathrm{M}$, then $\mathrm{M}_{2}$ has $\delta^{*}$ - supplement in M.

Proof Since $\mathrm{M}_{1}+\mathrm{M}_{2}$ has a $\delta^{*}$ - supplement in $\mathrm{M}$, so there exist a submodule $\mathrm{L}$ of $\mathrm{M}$ such that $\mathrm{M}=$ $\left(\mathrm{M}_{1}+\mathrm{M}_{2}\right)+\mathrm{L}$ and $\left(\mathrm{M}_{1}+\mathrm{M}_{2}\right) \cap \mathrm{L}<<\mathrm{L}$. Furthermore $\mathrm{M}_{1}$ is $\delta^{*}$-supplement with the submodule $\mathrm{M}_{2}+\mathrm{L} \cap \mathrm{M}_{1}$ of $\mathrm{M}_{1}+\mathrm{M}_{2}$, hence $\left(\mathrm{M}_{2}+\mathrm{L}\right) \cap \mathrm{M}_{1}$ is semisimple submodule of $M_{1}+M_{2}$. But $M_{1} \leq M_{1}+M_{2}$, so $M_{1}$ is also semisimple (since $\left(\mathrm{M}_{1}+\mathrm{M}_{2}\right)$ is semisimple). Hence $\left(M_{2}+L\right) \cap M_{1}$ is semisimple in $M_{1}$. This means that there exists a submodule $\mathrm{K}$ of $\mathrm{M}_{1}$ such that $\left(\left(\mathrm{M}_{2}+\mathrm{L}\right) \cap \mathrm{M}_{1}\right)+\mathrm{K}=\mathrm{M}_{1}$ with $\left(\left(\mathrm{M}_{2}+\mathrm{L}\right) \cap \mathrm{M}_{1}\right) \cap \mathrm{K}$

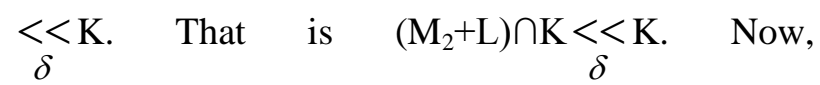
$\mathrm{M}=\mathrm{M}_{1}+\mathrm{M}_{2}+\mathrm{L}=\left(\left(\left(\mathrm{M}_{2}+\mathrm{L}\right) \cap \mathrm{M}_{1}\right)+\mathrm{K}\right)+\mathrm{M}_{2}+\mathrm{L}=$ $\mathrm{M}_{2}+(\mathrm{K}+\mathrm{L})$. Since $\mathrm{M}_{2} \cap(\mathrm{K}+\mathrm{L}) \leq\left(\left(\mathrm{M}_{2}+\mathrm{M}_{1}\right) \cap \mathrm{L}\right)+$ $\left(\left(\mathrm{M}_{2}+\mathrm{L}\right) \cap \mathrm{K}\right)$. So $\mathrm{M}_{2} \cap(\mathrm{K}+\mathrm{L})<<\mathrm{K}+\mathrm{L}$. But $\mathrm{M}_{2}$ is semisimple. Thus $\mathrm{M}_{2}$ is $\delta^{*}$ - supplement of $\mathrm{K}+\mathrm{L}$ in M.

The following proposition gives some properties of $\delta^{*}$ - supplemented modules

Proposition 18 Let M be an R-module, N and K be submodules of $\mathrm{M}$ such that $\mathrm{K}$ is $\delta^{*}$ - supplement of $\mathrm{N}$ then

1. If $\mathrm{W}+\mathrm{K}=\mathrm{M}$ for some submodule $\mathrm{W}$ of $\mathrm{N}$ then $\mathrm{K}$ is $\delta^{*}$ - supplement of $\mathrm{W}$.

2. If $\mathrm{K}$ is $\delta^{*}$ - supplement of $\mathrm{L} \leq \mathrm{M}$, then $\mathrm{K}$ is $\delta$ *- supplement of $\mathrm{N}+\mathrm{L}$.

3. If $\mathrm{L} \leq \mathrm{N}$, then $\frac{K+L}{L}$ is $\delta^{*}$ - supplement of $\frac{N}{L}$ in $\frac{M}{L}$.

\section{Proof}

1. Since $\mathrm{K}$ is $\delta^{*}$ - supplement of $\mathrm{N}$ thus $\mathrm{K}$ is semisimple submodule of $\mathrm{M}$ and $\mathrm{N}+\mathrm{K}=\mathrm{M}$, $\mathrm{N} \cap \mathrm{K} \underset{\delta}{<<}$. But $\mathrm{W} \leq \mathrm{N}$ and $\mathrm{W} \cap \mathrm{K} \leq \mathrm{N} \cap \mathrm{K} \underset{\delta}{<<}$,

so $\mathrm{W} \cap \mathrm{K}<<\mathrm{K}(8$,lemma1.3-1). Therefore $\mathrm{K}$ is $\delta^{*}$ - supplement of W.

2. Since $\mathrm{K}$ is $\delta^{*}$ - supplement of $\mathrm{N}$ thus $\mathrm{K}$ is semisimple submodule of $\mathrm{M}, \mathrm{N}+\mathrm{K}=\mathrm{M}$ and $\mathrm{N} \cap \mathrm{K}<<\mathrm{K}$. Also $\mathrm{K}$ is $\delta^{*}$ - supplement of $\mathrm{L}$, thus $\mathrm{K}+\mathrm{L}=\mathrm{M}$ and $\mathrm{K} \cap \mathrm{L}<<\mathrm{K}$. Therefore $\mathrm{M}=$ $\mathrm{N}+\mathrm{L}+\mathrm{K}$ and by Modular law
$(\mathrm{N}+\mathrm{L}) \cap \mathrm{K}=(\mathrm{N} \cap \mathrm{K})+(\mathrm{L} \cap \mathrm{K}) \underset{\delta}{<}<\mathrm{K}(8$, lemma1.3-

1). Hence $K$ is $\delta^{*}$ - supplement of $N+L$.

3. Suppose that $\mathrm{N}+\mathrm{K}=\mathrm{M}$ and $\mathrm{N} \cap \mathrm{K}<<\mathrm{K}$ ( $\mathrm{K}$ is $\delta^{*}$ - supplement of $\left.\mathrm{N}\right)$. Now, $\mathrm{L} \leq \mathrm{N}, \mathrm{N} \cap(\mathrm{K}+\mathrm{L})=$ $(\mathrm{N} \cap \mathrm{K})+\mathrm{L}$ (modularity) and $\frac{N}{L} \cap \frac{K+L}{L}=\frac{(\mathrm{N} \cap \mathrm{K})+L}{L}$. Since $\mathrm{N} \cap \mathrm{K}<\delta$ K thus $\frac{(\mathrm{N} \cap \mathrm{K})+L}{L}<<\frac{K+L}{L} \quad(8$, lemma1.3-1). Now, the assertion follows from $\frac{N}{L}+\frac{K+L}{L}=\frac{M}{L}$.

An R-module is called " $\delta$-hollow if every proper submodule of $\mathrm{M}$ is $\delta$-small (1)". The following proposition shows that the classes of $\delta$-hollow modules is an embedding in the classes of $\delta^{*}$ supplemented modules.

Proposition 19 Every $\delta$-hollow module is $\delta^{*}$ supplemented module.

\section{Proof}

Let $\mathrm{N}$ be a semisimple submodule of $\delta$-hollow module $M$. Thus by (8), $M=N \oplus K$, for $K \leq M$. Then by $\mathrm{N}=\mathrm{N} \oplus(\mathrm{N} \cap \mathrm{K})$. Since $\mathrm{M}$ is $\delta$-hollow, thus $\mathrm{N}<<$

$\mathrm{M}$ and $\mathrm{N} \cap \mathrm{K} \leq \mathrm{N}$, hence $\mathrm{N} \cap \mathrm{K}<<\mathrm{M}$. Therefore by theorem $11 \mathrm{M}$ is $\delta^{*}$-supplemented.

\section{Examples 20}

1. The $\mathbb{Z}_{6}$-module $\mathbb{Z}_{6}$ and the $\mathbb{Z}$-modules $\mathbb{Z}_{4}$, $\mathbb{Z}_{p^{\infty}}, \mathbb{Z}_{8}$ are $\delta$-hollow(1), and hence they are $\delta^{*}$ - supplemented.

2. The converse of the last Proposition is not true as the following example:

The $\mathbb{Z}$-module, $\mathbb{Z}_{12}$ is $\delta^{*}$-supplemented since $\mathbb{Z} \quad 12$ has only one semisimple submodule which is $\langle\overline{2}\rangle$, and $\mathbb{Z}_{12}=\langle\overline{4}\rangle$ $\oplus\langle\overline{3}\rangle,\langle\overline{4}\rangle \leq\langle\overline{2}\rangle$ and $\langle\overline{2}\rangle \cap<\overline{3}\rangle=<$ $\overline{6}><<<\overline{3}>$ by Theorem11, $\mathbb{Z}{ }_{12}$ as $\mathbb{Z}-$ module is $\delta^{*}$ - supplemented but $\mathbb{Z} 12$ as $\mathbb{Z}$ module is not $\delta$-hollow(1).

Corollary 21 Every hollow module is $\delta^{*}$ supplemented module.

Proof It's an obvious, since every hollow is $\delta$ hollow, and by proposition 19 the proof is omitted.

The converse is not true for example, $Q$ as $\mathbb{Z}$ module is $\delta^{*}$ - supplemented module but not hollow module.

Corollary 22 Every indecomposable and $\delta$-lifting module is $\delta^{*}$ - supplemented.

Proof By (1, proposition 3.8) every indecomposable and $\delta$-lifting is $\delta$-hollow and by proposition 19, M is $\delta^{*}$ - supplemented module. 
Following (5), a module $\mathrm{M}$ is " $\delta$-local if, $\delta(\mathrm{M})$ $<<\mathrm{M}$ and $\delta(\mathrm{M})$ is a maximal submodule of M".

Corollary 23 Every local ( $\delta$-local) module is $\delta^{*}-$ supplemented module.

Remark 24 The converse of corollary 23 is not true in general: $\mathbb{Z}_{12}$ as $\mathbb{Z}$-module is $\delta^{*}$ - supplemented module but not local module.

\section{Conflicts of Interest: None.}

\section{References:}

1. Hadi I M A, Aidi S H,$\delta$-Hollow Modules, IJPAS. 2014; 27 (2) .
2. Onal E, Calisici H, Turkmen E, Modules that have a Weak Supplement in every Extension, MMN. 2016; 17 (1), 471-481.

3. Nebiyev C, On a Generalization of Supplement Submodules, IJPAM. 2017; 113(2), 283-289.

4. Wisbauer R, Foundation of Module and Ring Theory, 1991, Gordon

5. Abdioglu C, Sahinkaya S, Some Results on $\delta$-Semi Perfect Rings and $\delta$ - Supplemented Submodules, MJ. 2015; 55, (2), 289-300.

6. Bilhan G, Groglu A T, A variation of Supplemented Modules, TJM.2013; 37, 418- 426.

7. Hassan S S, Some Generalizations of $\delta$-Lifting Modules, 2011, M.Sc. Thesis, University of Baghdad.

8. Nemalallal M J, On $\delta$-Supplemented Submodules, Tarbiat Modlen Univ., $20^{\text {th }}$ Seminar on Algrbra 2-3 Ordibeheshtm, 2000; 1388 (Apr.22-23), 155-15.

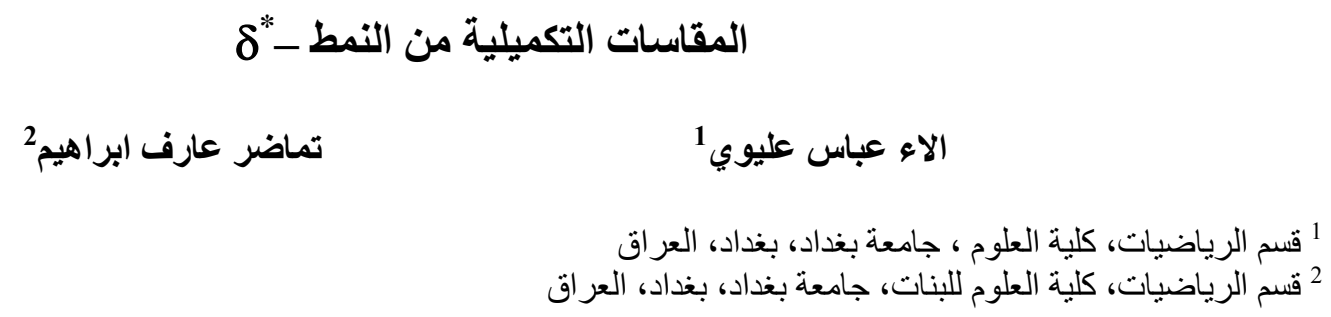

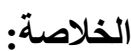

الهذف الرئيسي من هذا البحث هو تقديم ودر اسة مفهوم جديد اسميناه مقاسات تكميلية من النمط - *ك و التي يمكن اعتبار ها إعمام

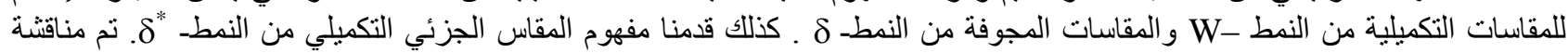

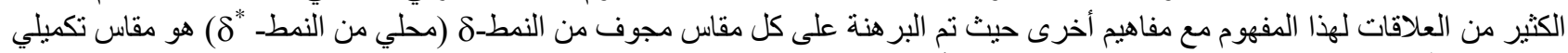

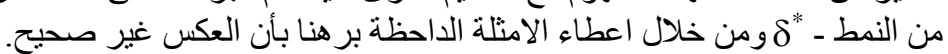

الكلمات المفتاحية : المقاسات المجوفة من النمط - $\delta$ ، المقاسات الجزئية الصغيرة من النمط ك، المقاسات التكميلية من النمط ـ * ، المقاسات التكميلية من النمط -W- 